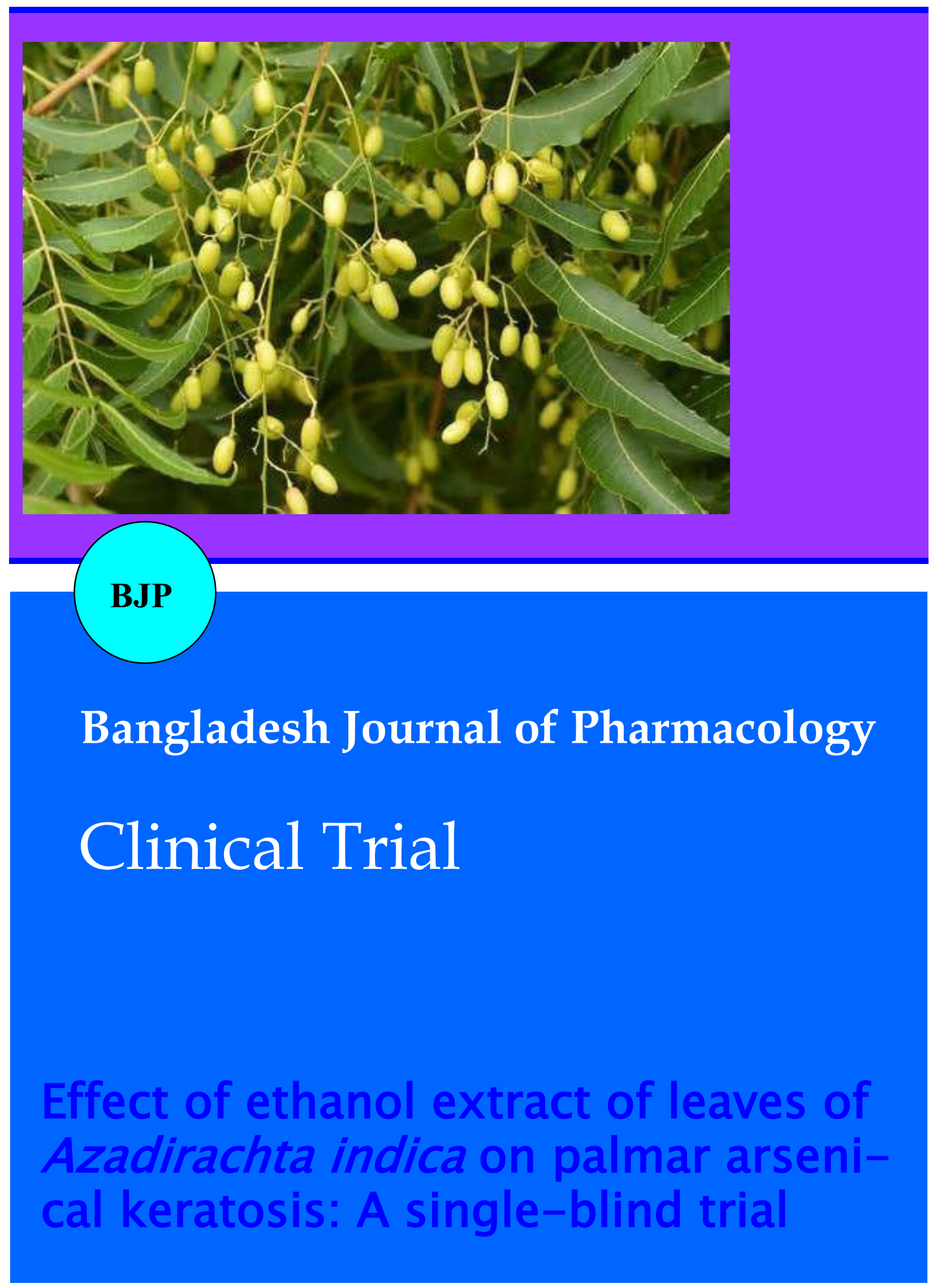




\section{Effect of ethanol extract of leaves of Azadirachta indica on palmar arsenical keratosis: A single-blind trial}

Jannatul Ferdoush and Mir Misbahuddin

Department of Pharmacology, Faculty of Basic Science and Paraclinical Science, Bangabandhu Sheikh Mujib Medical University, Shahbag, Dhaka, Bangladesh.

\begin{tabular}{|c|c|}
\hline \multicolumn{2}{|l|}{ Article Info } \\
\hline Received: & 2 June 2014 \\
\hline Accepted: & 10 June 2014 \\
\hline Available Online: & 13 July 2014 \\
\hline \multicolumn{2}{|c|}{ DOI: 10.3329/bjp.v9i3.19488 } \\
\hline \multicolumn{2}{|c|}{$\begin{array}{l}\text { Cite this article: } \\
\text { Ferdoush J, Misbahuddin M. Effect of } \\
\text { ethanol extract of leaves of Azadirachta } \\
\text { indica on palmar arsenical keratosis: A } \\
\text { single-blind trial. Bangladesh J Phar- } \\
\text { macol. 2014; 9: 279-83. }\end{array}$} \\
\hline
\end{tabular}

\section{Abstract}

The effectiveness of topical application of ethanol extract of Azadirachta indica (neem) daily for 12 weeks was examined in patient of palmar arsenical keratosis. The mean $( \pm S D)$ score of size of nodules of patients $(n=14)$ using salicylic acid alone before and after treatment were $14.6 \pm 4.6$ and $10.5 \pm 4.5$ respectively (28.1\% improvement). The mean score of size of nodules of patients $(\mathrm{n}=15)$ using salicylic acid plus $A$. indica (ethanol extract) before treatment was $14.7 \pm 4.6$ which was decreased to $3.1 \pm 2.2$ after treatment $(79 \%$ improvement). The perception score of salicylic acid-treated group was 2.1 whereas it was increased to 4.7 in A. indica plus salicylic acid-treated group. Based on palmar nodular size and patients perception it can be concluded that topical use of ethanol extract of $A$. indica is effectively in palmar arsenical keratosis.

\section{Introduction}

Chronic consumption of arsenic more than $50(\mu \mathrm{g} / \mathrm{L})$ through contaminated drinking water can cause the skin manifestations (melanosis, leucomelanosis and keratosis) that are the most diagnostic in arsenicosis (Ahmad et al., 1997). Arsenical keratosis usually appears on palm and planter aspect of the feet and may also develop on the dorsum of the extremities and trunk (Caussy, 2005).

Treatment of all types of keratosis is difficult. The most common therapeutic option leads to short-term improvement and is frequently compounded by various adverse effects. Treatment tends to be symptomatic and includes topical keratolytics, orally administered anti-oxidant vitamins and minerals, or reconstructive surgery with total excision of the keratotic skin followed by grafting. Topical keratolytics (e.g. salicylic acid $10-20 \%$, lactic acid $10 \%$, urea $10-40 \%$ ) are useful in patients with limited keratosis. Topical retinoid (e.g. tretinoin) is effective, but treatment is often limited by skin irritation. Potent topical steroids also use with or without keratolytics with an inflammatory component.

Arsenical keratosis can be treated by either topical administration of drug or oral administration of dietary supplement or both. Oral supplementation of retinol and beta-carotene is beneficial in the treatment of arsenicosis was first described more than fifty years ago (Hall, 1946). Combination of vitamin A, E and C are used to treat the case of arsenicosis (Ahmad et al., 1998). Ascorbic acid, alpha-tocopherol, zinc (Kamaluddin and Misbahuddin, 2006), folic acid (Rahman and Misbahuddin, 2010), alpha-lipoic acid (Tabassum, 2006), and selenium (Nasir et al., 2002) were found to be effective in the removal of tissue arsenic thereby reducing body arsenic load and improve clinical symptoms in skin manifestation in both animal models and patients. Longer duration (3-14 months) of treatment make it costly which ultimately affects patient's adherence. In addition, stoppage of supplementation recurs the symptoms of keratosis.

Some of our foodstuffs have the capability to remove arsenic from the body. These include corn (Chowdhury 
et al., 2009), spinach (Umar, 2007), garlic oil (Misbahuddin and Tahmina, 2010) Amaranthus esculentus leaves (locally called data shak) and spirulina (Misbahuddin et al., 2006). But among topical administration only salicylic acid (Islam et al., 2007) and propylene glycol (Dina and Misbahuddin, 2010) improves the symptoms by soothing effect. There are no other drugs which can be applied topically. Rather these drugs also cause side effects like burning sensation, itching and irritation. So, an investigation is required to search for a new drug which can be administered topically causing fewer side effects in addition to being effective.

Medicinal plants have received substantial notice in the drug discovery process for various human disorders. Among the medicinal plants Azadirachta indica commonly known as neem, is distributed widespread in the world and has enormous medicinal value. Different parts of the $A$. indica have been utilized as conventional medicine in India for long time (Varma, 1974). Neem leaf and bark extracts, oil has been used therapeutically as folk medicine to treat leprosy, respiratory disorders, and constipation and also as a health promoter (Kirtikar and Basu, 1975). It has also been use in the treatment of rheumatism, chronic syphilitic sores, and indolent ulcer. It has also been use in the treatment of rheumatism, chronic syphilitic sores and indolent ulcer (Kirtikar and Basu, 1975). In various skin infections $A$. indica oil is used to control (Chopra et al., 1956).

Since A. indica is partlicularly well-known for its medicinal use in the treatment of common skin diseases and conditions including eczema, acne, psoriasis, pityriasis-versicolor (Parrotta, 2001; Banu, 2011; Pandey, 1994; Aremu, 2008). It can be presumed that palmar arsenical keratosis can be reduced by using $A$. indica leaf extract on the keratotic lesion. So, the current study will explore the possibility and efficiency of using A. indica leaf extract for the treatment of palmar arsenical keratosis.

\section{Materials and Methods}

\section{Place and duration of the study}

This randomized controlled trial was conducted at Rajapur village of Rajapur union (Union 2) and Masimpur village of jaylashkar union (Union 8) of Dagonbhuiyan Upazilla of Feni, about $165 \mathrm{~km}$ from Dhaka. Rajapur and Masimpur village of Dagonbhuiyan Upazilla are arsenic affected areas where a large number of people are consuming high concentration of arsenic through drinking water. The total duration of study from protocol writing to data analysis was from September 2012 to February 2014.

\section{Participants}

List of the palmar arsenical keratosis patients and their addresses were collected from Upazilla Health complex of Dagonbhuiyan. Each patient was informed to visit a Temporary Arsenic Clinic (house of a patient). Detailed history, clinical examination and photographs (both palms) were collected. After clinical examination, as well as collection of drinking water and estimation of arsenic in nail confirmed 44 cases of moderate palmar arsenical keratosis patients. The objective, nature, potential risks and benefits of all procedures of the study were explained in details to the patients. Written informed consent was taken from each patient.

\section{Collection of samples}

Properly labeled container was supplied to all participants of the study. $10 \% \mathrm{HNO}_{3}$ (one drop) was added to each container for collecting drinking water in order to inhibit the microbial growth after collection. Drinking water (50-100 mL), nail (200-500 mg) samples were collected and transported to the Department of Pharmacology. The participants at first washed and dried their hands; nail samples were collected from all the fingers and were stored in a dry container. Drinking water and nail samples were kept in a cool, dry corner of a room before analysis.

\section{Randomization of patients}

There were about 94 patients of arsenicosis of which. 66 patients were suffering from moderate arsenical keratosis (Health Complex of Feni, October 2012). Randomizations of the patients for both groups were done by using Software by using random number generator.

\section{Inclusion criteria}

It included a) age: 18-60 years; b) sex: both male and female; c) arsenical keratosis present on palm; d)

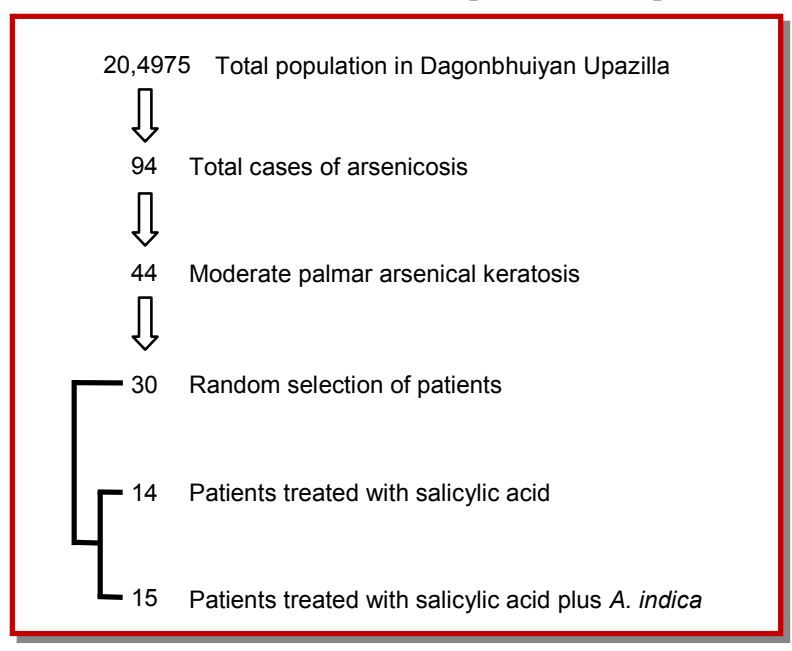

Figure 1: Steps of selection of patients 
drinking arsenic contaminated water $(>50 \mu \mathrm{g} / \mathrm{L})$ for more than 6 month; and e) patient voluntarily agreed to participate.

\section{Exclusion criteria}

It included a) patients' age being less than 18 or over 60 years; b) pregnant and lactating mother; c) psoriasis and eczema; d) Bowen's disease; e) any kind of systemic disease, inflammatory disease and infectious condition that affect skin (diabetes mellitus, RA, SLE, hepatitis); f) hypersensitivity to any drug; g) patient who received treatment within the last three months and $h$ ) patients did not voluntarily agree to participants.

\section{Ethical consideration}

Institutional Review Board of Bangabandhu Sheikh Mujib Medical University (BSMMU) was reviewed and approved the ethical issue of the study. All the participants of the study were explained the objective, nature, purpose and potential risks and benefits of all procedures of the study in easily understandable language (Bangla). The participants were informed that they have every right to seek better treatment and also withdraw themselves from the study. Although every care were taken to look after and monitoring the patients in case of any complications. Written informed consent was taken from each subject.

\section{Data collection procedures}

After taking informed written consent, detailed history was taken by interviewing and clinical examinations were done mainly based on arsenical keratosis of palm of the participants and recorded in data collection sheet. The result of the study was recorded in separate result sheet.

\section{Collection of leaf of $A$. indica}

Fresh matured leaves of $A$. indica were collected from the local area. About $7 \mathrm{~kg}$ leaves were collected.

\section{Procedure of obtaining ethanol extract of A. indica}

The leaves which weight $7 \mathrm{~kg}$ were separated from stem, washed with tap water and dried in a cool place of the laboratory for 5 days. As a result, the weight of leaves was reduced to about $3.7 \mathrm{~kg}$ which was then grinded into powder with an electric blender. About 2.2 $\mathrm{kg}$ powder was suspended in $11 \mathrm{~L}$ of $70 \%$ ethanol in an amber color container for 72 hours in a dark cool place. The whole was then filtered with filter paper. The filtrate was concentrated with the help of rotary vacuum evaporator at temperature $\left(50^{\circ} \mathrm{C}\right)$. About $330 \mathrm{~g}$ of condensed ethanol extract of $A$. indica was obtained. Extract was then preserved in amber colored glass bottle in refrigerator.

Preparation of $10 \%$ A. indica and 6\% salicylic acid ointment

From $330 \mathrm{~g}$ ethanol extract of $A$. indica, $300 \mathrm{~g}$ of extract and $180 \mathrm{~g}$ salicylic acid mixed properly with 2,520 $\mathrm{g}$ petroleum jelly. Thus 3,000 $\mathrm{g}$ of $A$. indica plus salicylic acid ointment was prepared. Then about 15 to $20 \mathrm{~g}$ of ointment was taken in each container.

\section{Preparation of 6\% salicylic acid ointment}

Salicylic acid (180 g) was mixed properly with 2,820 $\mathrm{g}$ of petroleum jelly. Then about 15 to $20 \mathrm{~g}$ of ointment was taken in each container.

\section{Distribution of ointment}

Each patient received a plastic container containing $10 \%$ A. indica plus $6 \%$ salicylic acid ointment or $6 \%$ salicylic acid in petroleum jelly base. Patients were instructed to apply the drug to the affected area on the palm at bed time once daily after washing hand properly.

\section{Periodic monitoring of patient}

Patient compliance sheet were supplied to the patient and instructed to give tick mark after using the drug on respected date. Adverse effect follow-up sheet was also provided and if any side effects arise the patient was instructed to give tick mark on the respected date and report to the researcher. Regular monitoring was done by cell phone. The ointment was supplied every 2 weeks interval for 12 weeks. Patients were asked to report to the researcher on a fixed date at the clinic every 2 weeks interval. Photo-graphs were taken before and after completion of treatment. Measurement of the nodule size before treatment started and after completion of 12 weeks treatment.

\section{Perception scale of patients about their improvement of palmar keratosis}

Perception of the patient about his/her improvement of symptoms were graded according to an originally modified Lickert scale (Rensis, 1932) used for this study are given below on Table I. The reliability of this scale was tested during a pilot study before starting this study. The perception scale was translated to Bangla so that the patient can easily understand.

Arsenic was estimated by SDDC method (AOAC, 1975). In brief: Samples were digested followed by arsine generated. In an arsine generator, inorganic arsenic was reduced to arsine $\left(\mathrm{AsH}_{3}\right)$ by zinc in strong acid solution. Then the arsine was passed through a scrubber containing cotton wool wetted with lead acetate into an absorber tube containing SDDC dissolved in chloroform. A soluble red color complex formed whose absorbance was read in spectrophotometer (UV-VIS spectrophotometer-1201, Shimadzu, Japan) at $525 \mathrm{~nm}$, when arsine reacting with the silver salt.

\section{Results}

Table II shows similarities in two treated groups. There was one drop out case in salicylic acid treated group. 


\begin{tabular}{|c|c|c|c|}
\hline \multicolumn{4}{|c|}{ Table I } \\
\hline \multicolumn{4}{|c|}{$\begin{array}{l}\text { Perception scale of patient about his/her improve- } \\
\text { ment of palmar arsenical keratosis }\end{array}$} \\
\hline \multicolumn{4}{|c|}{ Grade $0 \quad$ No change } \\
\hline \multicolumn{4}{|c|}{ Grade 1 Slight softening of visible lesions } \\
\hline Grade 2 & \multicolumn{3}{|c|}{ Softening plus reduction of size of some lesions } \\
\hline Grade 3 & \multicolumn{3}{|c|}{$\begin{array}{l}\text { Softening plus disappearance of some smaller } \\
\text { nodules }\end{array}$} \\
\hline Grade 4 & \multicolumn{3}{|c|}{$\begin{array}{l}\text { Softening plus disappearance of some larger } \\
\text { nodules }\end{array}$} \\
\hline Grade 5 & \multicolumn{3}{|c|}{$\begin{array}{l}\text { Deletion of maximum nodules and almost } \\
\text { cured }\end{array}$} \\
\hline \multicolumn{4}{|c|}{ Table II } \\
\hline \multicolumn{4}{|c|}{ Characteristics of the participants } \\
\hline \multicolumn{2}{|c|}{ Characteristics } & $\begin{array}{l}\text { Salicylic } \\
\text { acid }\end{array}$ & $\begin{array}{l}\text { A. indica plus } \\
\text { salicylic acid }\end{array}$ \\
\hline \multicolumn{2}{|c|}{ No. of participants } & 14 & 15 \\
\hline \multicolumn{2}{|c|}{ Age (years) } & $\begin{array}{r}40.2 \\
(13.8)\end{array}$ & $\begin{array}{l}42.9 \\
(9.0)\end{array}$ \\
\hline \multicolumn{2}{|c|}{$\begin{array}{l}\text { Amount of arsenic in tube well } \\
\text { water }(\mu \mathrm{g} / \mathrm{L})\end{array}$} & $\begin{array}{r}99.2 \\
(18.1)\end{array}$ & $\begin{array}{l}124.6 \\
(85.9)\end{array}$ \\
\hline \multicolumn{2}{|c|}{$\begin{array}{l}\text { Amount of arsenic in nail }(\mu \mathrm{g} / \\
\mathrm{g})\end{array}$} & $\begin{array}{r}1.3 \\
(0.3)\end{array}$ & $\begin{array}{r}1.2 \\
(0.6)\end{array}$ \\
\hline \multicolumn{2}{|c|}{$\begin{array}{l}\text { Duration of arsenic exposure } \\
\text { (Year) }\end{array}$} & $\begin{array}{l}17.4 \\
(8.1)\end{array}$ & $\begin{array}{l}19.2 \\
(6.6)\end{array}$ \\
\hline \multicolumn{2}{|c|}{$\begin{array}{l}\text { Duration of signs and symp- } \\
\text { toms (Year) }\end{array}$} & $\begin{array}{r}8.4 \\
(4.7)\end{array}$ & $\begin{array}{r}8.7 \\
(3.0)\end{array}$ \\
\hline \multicolumn{2}{|c|}{ Duration of melanosis (Year) } & $\begin{array}{r}7.1 \\
(4.1)\end{array}$ & $\begin{array}{r}8.5 \\
(4.7)\end{array}$ \\
\hline \multicolumn{2}{|c|}{ Duration of keratosis (Year) } & $\begin{array}{r}6.2 \\
(3.1)\end{array}$ & $\begin{array}{r}7.7 \\
(4.9)\end{array}$ \\
\hline
\end{tabular}

Total size of the nodule was measured in both groups (Table III). The mean size of nodule in salicylic acid alone treated group was $14.6 \pm 4.6$ before treatment and $10.5 \pm 4.5$ after 12 weeks of treatment ( $28.1 \%$ reduction). The mean size of nodule in $A$. indica plus salicylic acid treated group was $14.7 \pm 4.6$ before treatment and $3.1 \pm$ 2.2 after treatment (79\% reduction). The perception score of salicylic acid-treated group was 2.1 whereas it was increased to 4.7 in A. indica plus salicylic acidtreated group (Table IV).

There was no remarkable side effects occurred during 12 weeks of therapy. Only two patients who were using salicylic acid alone experienced slight burning during drug use. One patient who was using $A$. indica plus salicylic acid complained foul smell about the drug. Rest of participants complained no problem during drug application.

\section{Discussion}

The present study shows that topical application of

\begin{tabular}{|c|c|c|c|c|c|c|}
\hline \multicolumn{7}{|c|}{ Table III } \\
\hline \multicolumn{7}{|c|}{ Measurement of nodule size } \\
\hline \multicolumn{4}{|c|}{$\begin{array}{l}\text { Salicylic acid only } \\
\qquad(\mathrm{n}=14)\end{array}$} & \multicolumn{3}{|c|}{$\begin{array}{l}\text { A. indica plus salicylic acid } \\
\qquad(\mathrm{n}=15)\end{array}$} \\
\hline $\begin{array}{l}\text { Before } \\
\text { study }\end{array}$ & After & \multicolumn{2}{|c|}{$\begin{array}{l}\text { Reduc- } \\
\text { tion }\end{array}$} & $\begin{array}{l}\text { Before } \\
\text { study }\end{array}$ & $\begin{array}{l}\text { After } \\
\text { study }\end{array}$ & $\begin{array}{l}\text { Reduc- } \\
\text { tion }\end{array}$ \\
\hline 11 & 9 & & & 14 & 2 & \\
\hline 15 & 13 & & & 18 & 0 & \\
\hline 17 & 10 & & & 19 & 3 & \\
\hline 14 & 10 & & & 10 & 4 & \\
\hline 12 & 8 & & & 12 & 2 & \\
\hline 20 & 15 & & & 13 & 3 & \\
\hline 12 & 7 & & & 11 & 3 & \\
\hline 26 & 23 & & & 17 & 5 & \\
\hline 20 & 14 & & & 16 & 2 & \\
\hline 11 & 6 & & & 22 & 4 & \\
\hline 10 & 8 & & & 15 & 9 & \\
\hline 11 & 9 & & & 8 & 0 & \\
\hline 14 & 6 & & & 23 & 4 & \\
\hline 12 & \multirow[t]{2}{*}{9} & & & 9 & 2 & \\
\hline & & & & 24 & 0 & \\
\hline $\begin{array}{l}14.6 \mathrm{a} \\
(4.6)\end{array}$ & $\begin{array}{l}10.5 \mathrm{a} \\
(4.5)\end{array}$ & \multicolumn{2}{|c|}{$28.1 \%$} & $\begin{array}{l}14.7 \mathrm{a} \\
(4.6)\end{array}$ & $\begin{array}{l}3.1^{a} \\
(2.2)\end{array}$ & $79.0 \%$ \\
\hline \multicolumn{7}{|c|}{ aData were presented as mean. Value within parenthesis is SD } \\
\hline \multicolumn{7}{|c|}{ Table IV } \\
\hline \multicolumn{7}{|c|}{$\begin{array}{l}\text { Perception scores of patients about their improve- } \\
\text { ment }\end{array}$} \\
\hline \multirow[t]{2}{*}{$\begin{array}{l}\text { Perception } \\
\text { score }\end{array}$} & \multicolumn{3}{|c|}{$\begin{array}{c}\text { Salicylic } \\
\text { acid } \\
(\mathrm{n}=14)\end{array}$} & \multicolumn{2}{|c|}{$\begin{array}{c}\text { A. indica plus } \\
\text { salicylic acid } \\
(\mathrm{n}=15)\end{array}$} & \\
\hline & & & $\begin{array}{l}\text { To } \\
\text { sco }\end{array}$ & & & $\begin{array}{l}\text { Total } \\
\text { score }\end{array}$ \\
\hline 0 & & L & 0 & & 0 & 0 \\
\hline 1 & & 2 & 2 & & 0 & 0 \\
\hline 2 & & 5 & 10 & & 0 & 0 \\
\hline 3 & & 5 & 18 & & 1 & 3 \\
\hline 4 & & ) & 0 & & 5 & 20 \\
\hline 5 & & ) & c & & 6 & 30 \\
\hline 6 & & ) & 0 & & 3 & 18 \\
\hline Mean & & & 2.1 & & & 4.7 \\
\hline
\end{tabular}

ethanol extract of leaf of $A$. indica had significant effect in curing arsenical keratotic lesion. During the study period no side effects observed except one patient complained of foul odor.

A randomized controlled trial showed the effectiveness of topical use of salicylic acid for the treatment of palmar arsenical keratosis (Islam et al., 2007). In that study 5, 10, 20, 30\% concentration of salicylic acid were used in mild, moderate and severe cases of palmar arsenical keratosis patients twice daily for 6 month. The concentration of the ointment which had been found to be more effective in the treatment of moderate palmar keratosis was 20 and $30 \%$ of salicylic acids ointment.

A. indica probably act by inhibiting the accelerated proliferation of keratinocytes, A. indica leaf extract, 
which contains nimbidin as a major part had shown antitumor properties (Van der Nat, 1991).

Another randomized double blind trial showed the effectiveness of topical use of propylene glycol $(15,30$, $45 \%)$ in the treatment of palmar arsenical keratosis (Dina and Misbahuddin, 2010). Here perceptions of patient about their improvement were taken at different stage. But no clinical assessment had done. Follow up was conducted at 1 month interval.

In this study two type of assessment was done. Here perception scoring of patient and clinical assessment of patient's improvement of palmar keratosis was done by measuring nodule size before and after treatment. Regular monitoring was done through phone calls and follow-up visit at 2 weeks interval. This provides conformation that the patients were applying the medicine as instructed.

In conclusion, $A$. indica leaf extract can be used effectively as topical treatment of palmar arsenical keratosis.

\section{References}

Ahmad SA, Bandaranayake D, Khan AW, Hadi SA, Uddin U, Halim MA. Arsenic contamination in ground water and arsenicosis in Bangladesh. Int J Environ Health Res. 1997; 7: 271-76.

Ahmad SK, Faruquee MH, Sayed MHSU, Khan MH, Hadi SA, Khan AW. Chronic arsenic poisoning: Management by vitamin A, E, C regimen. J Pre Social Med (JOPSOM). 1998; 17: 19-26.

Aremu OI, Femi-Oyewo MN. Antifungal effect of topically administered neem (Azadirachta Indica) seed oil cream against Pytiriasis versicolour. J Pharmaceut Allied Sci. 2008; 5: 591-605.

AOAC (Association of Official Analytical Chemists 25. 006) 12th ed. 1975, p 428.

Banu ALE, Humnekar A. A prospective study to determine the effectiveness of clindamycin (allopathy), Berberis aquifolium (oregon grape-homeopathy) and Azadirachta indica (neemayurvedic) medications against the microorganism causing acne vulgaris. Int J Basic Med Sci. 2011; 2: 78-83.

Caussy D. A field guide for detection, management and surveillance of arsenicosis cases. New Delhi, WHO Regional Office for South-East Asia, 2005.

Chopra RN, Nayer SL, Chopra IC. Glossary of Indian medicinal plants. New Delhi, CSIR, 1956.

Chowdhury NJA, Misbahuddin M, Rahman MS. Corn extracts lower tissue arsenic level in rat. Bangladesh Med Res Counc Bull. 2009; 35: 21-25.
Dina AN, Misbahuddin M. Randomized double-blind trial to evaluate the effectiveness of topical administration of propylene glycol in arsenical palmer keratosis. Bangladesh J Pharmacol. 2010; 5: 98-102.

Hall AF. Arsenical keratosis disappearing with vitamin A therapy. Arch Derm Syph. 1946; 53: 154.

Islam AZM M, Sikdar S, Biswas AK, Islam Z, Hadiuzzaman, Misbauddin M, Khandaker S, Mahmud I, Ahmad SA. Randomized controlled trial to evaluate the effectiveness of topical use of salicylic acid for treatment of keratosis in arsenicosis patient. In: Applied research on arsenic in Bangladesh, 2007, p 101.

Kirtikar KR, Basu BD. Indian medicinal plants. Blatter E, Cains JF, Mhaskar KS. (eds). New Delhi, Vivek Vihar, 1975, p 536.

Misbahuddin M, Kamaluddin M. Simultaneous administration of zinc and arsenic enhances accumulation in tissues. BMJ. (Rapid response): 2002; 14.

Misbahuddin M, Islam AZ, Khandker S, Ifthaker-Al- Mahmud, Islam N, Anjumanara. Efficacy of spirulina extract plus zinc in patients of chronic arsenicosis poisoning: A randomized placebo-controlled study. Clin Toxicol (Phila). 2006; 44: 13541.

Misbahuddin M, Bashar T, Hossain MA. Effectiveness of garlic oil in the treatment of arsenical palmer keratosis. Bangladesh J Pharmacol. 2013; 8: 22-27.

Nasir M, Misbahuddin M, Ali SMK. Selenium intervention in reducing arsenic levels in different tissues. In: Bangladesh Environment 2002, Proceedings of the 2nd International Conference on Bangladesh Environment. Ahmed MF, Tanveer SA, Badruzzaman ABM (eds). ICBEN-2002, Dhaka, Bangladesh, 2002; 343-52.

Panda NP, Ray P. A study on effect of some indigenous plant extracts against two human pathogens. Asian J Exp Biol Sci. 2012; 3: 175-79.

Parrotta JA. Healing herbs of Penninsular India. Wallington, CABI Publishing, 2001, pp 495-97.

Rahman MF, Misbahuddin M. Effect of folic acid and tetrahydrofolate on tissue arsenic level in rat. Bangladesh J Pharmacol. 2010; 5: 25-29.

Rensis LA. A technique for the measurement of attitudes. Arch Psychol. 1932: 140: 1-55.

Tabassum NE. Effect of alpha-lipoic acid on the removal of arsenic from arsenic-loaded isolated liver tissues of rat. Bangladesh J Pharmacol. 2006; 1: 27-32.

Umar BU. Effect of hexane extract of spinach in the removal of arsenic from rat. Bangladesh J Pharmacol. 2007; 2: 27-34.

Varma GS. Miracles of neem tree. New Delhi, Rasayan Pharmacy, 1976.

Van der Nat JM, van der Sluis WG, de silva KT, Labadie RP. Enthnopharmacognostical survey of Azadirachta indica. J Enthnopharmacol. 1991; 35: 1-24. 